\title{
Relationship between protozoan and metazoan communities and operation and performance parameters in a textile sewage activated sludge system
}

\author{
Liliana Araújo dos Santos, Vânia Ferreira, Maria Olívia Pereira, Ana Nicolau* \\ CEB - Centre of Biological Engineering, University of Minho, 4710-057 Braga, Portugal
}

Received 16 May 2013; received in revised form 24 February 2014; accepted 19 March 2014

Available online 18 April 2014

\begin{abstract}
The present study aims at investigating the possibility of assessing performance and depuration conditions of an activated sludge wastewater treatment plant through an exploration of the microfauna. The plant, receiving textile industrial (70\%) and domestic (30\%) sewage, consists of a two-step biological depurating plant, with activated sludge followed by a percolating system. A total of 35 samples were analyzed during five months, and 30 taxa of protozoa and small metazoa were found. Epistylis rotans, Vorticella microstoma, Aspidisca cicada and Arcella sp. were the most frequent protozoa identified. Several significant correlations between biological, physical-chemical and operational parameters were determined, but no significant correlations could be established between biological parameters and removal efficiencies. The Sludge Biotic Index (SBI) reflected the overall state of the community but only presented statistically significant correlations with the influent total suspended solids (TSS), total suspended solids in mixed-liquor (MLTSS) and dissolved oxygen (DO). The determination of key groups and taxa along with general community parameters showed to have potential value as indicators of the depuration conditions. Despite the impossibility of correlating biological parameters and the removal efficiencies, the present study attests the value of the microfauna to assess the operation of the activated sludge systems even in the case of non-conventional plants and/or plants receiving industrial sewage.
\end{abstract}

(c) 2014 Elsevier GmbH. All rights reserved.

Keywords: Activated sludge; Biological indicators; Protozoa; Textile industrial sewage

\section{Introduction}

The identification of problems of wastewater treatment plants (WWTP) at the level of their microbial communities is now seen as an essential component of the monitoring of these systems. In the aeration tank of activated sludge systems, protozoa acquire special significance as they consume

\footnotetext{
*Corresponding author. Tel.: +351253 604423; fax: +351 253604429 .

E-mail address: protozoa@ deb.uminho.pt (A. Nicolau).
}

most of the dispersed bacteria in the mixed-liquor, and consequently take part in the reduction of suspended solids and turbidity in the final effluent (Al-Shahwani and Horan 1991). Thus, they significantly contribute to a better performance of the system (Madoni 1994; Madoni et al. 1993). Moreover, protozoa are especially sensitive to changes in the environmental conditions of the aeration tank and can be used as biological indicators, allowing for the evaluation of either the conditions inside the aeration tank or the performance of the system. Over the years, protozoa have been used as biological indicators in wastewater treatment in different ways. In 
the first place, authors established the relationships between the succession of different groups of protozoa and the temporal evolution of the system of activated sludge (Curds and Cockburn 1970). Others focused on the influence of physical and chemical conditions prevailing in the aeration tank, including the entry of toxicants (Abraham et al. 1997; Dubber and Gray 2011a; Madoni et al. 1993; Madoni et al. 1996; Mortimer et al. 2010; Nicolau et al. 2001; Nicolau et al. 2005; Nicolau et al. 2007; Papadimitriou et al. 2007). The accumulated knowledge helped to establish relationships between the prevalence of various groups of the microfauna and the performance of the plant, including the quality of the final effluent (Fried et al. 2000; Hu et al. 2013a; Hu et al. 2013b; Madoni et al. 1993; Salvadó et al. 1995) and specific species (Drzewicki and Kulikowska 2011; Pérez-Uz et al. 2010). Also, to study these complex ecosystems with many interacting factors, mathematical models proved to be useful tools complementing the observation of the microbial community (Holenda et al. 2008).

Frequent microscopic examination of biomass may provide a fast, simple and convenient method of indicating sudden changes in the plant performance. Methods based on the protozoan population structure have been used to assess activated sludge plant performance, the Sludge Biotic Index (SBI) proposed by Madoni (1994) being the best known and most common method here. This index is based on the abundance and diversity of the community of protozoa and small metazoa, as well as on the different sensitivities to changes in the environmental conditions prevailing in the aerating tank that are revealed by several of these groups.

The evolution of wastewater treatment systems driven forward through the introduction of new components/ technologies or sewage compounds in the activated sludgebased systems raised doubts about the applicability of the SBI to these new WWTP (Arévalo et al. 2009; Drzewicki and Kulikowska 2011; Dubber and Gray 2011a). Also, the addition of toxicants seems to affect the conclusions that can be drawn from the calculation of SBI (Drzewicki and Kulikowska 2011; Papadimitriou et al. 2007). Two different kinds of discrepancies between the SBI assessment and the effective quality of treatment have been described: in some cases, lowering of the treatment performance was not reflected by SBI values, that is, in spite of a decrease in the WWTP performance, the SBI values remained high (Drzewicki and Kulikowska 2011). Other authors, on the contrary, observed drastic effects on SBI values when the efficiency of the treatment systems remained high (Arévalo et al. 2009; Papadimitriou et al. 2007; Samaras et al. 2009). Drzewicki and Kulikowska (2011) suggested that changes in the abundance of some taxa of the microfauna could indicate, better than the SBI calculation, the performance level of the WWTP, namely the quality of the final effluent. Therefore, it is important to consider specific protozoan species as indicators of the performance of the plant. Yiannakopoulou and Kaimakamidou (2009) recommend the use of protozoan species as indicators; nevertheless they emphasize that the use of protozoan indicators should be limited to the empirical assessment of expert system development, and only to one particular plant.

In Portugal, many activated sludge WWTP receive significant amounts of sewage from textile industries, a fact that causes several problems to the management of these systems and leads to subsequent adaptations and upgrades in order to ensure the quality of the final effluent. In the textile sewage, a number of surfactants, dyes and heavy metals (e.g. copper and zinc) is present (Moran et al. 1997) bearing the potential to reduce the efficiency of biological wastewater treatments due to toxic phenomena. These compounds are also potentially toxic to the microfauna, thus complicating the interpretation of data in these cases.

The main goal of this study was to confirm the possibility of assessing the performance and the conditions of depuration of an industrial WWTP receiving textile sewage by using the protozoan and small metazoan communities. This was done through the establishment of relationships between the biological parameters, including the SBI, and the physical-chemical and operational parameters of the WWTP. The establishment of these relations is particularly important because data are scarce and some contradictions exist about these correlations in the scientific literature, as stated above.

\section{Material and Methods}

\section{Description of the wastewater treatment system}

The studied WWTP, located in Barcelos, Portugal, started working in 1999; it was projected as a percolating system to be used until 2020 by a constant population of 133,250 inhabitants. The wastewater is of industrial (70\%) and domestic (30\%) sources, with textile sewage as the major contribution. In the course of its operation, a significant change was made: due to the low performance of the initial design in removing solids, an activated sludge aerating tank followed by a settling tank was introduced before the percolating system. Therefore, this WWTP is at present composed of preliminary treatment (degreasing and desanding) and a two-step biological depurating system, including, by this order, an activated sludge aerating tank, a first settling tank, a percolating tank and a final settling tank. No selector or primary settling tank exists. The mean hydraulic retention time (HRT) in the five months was $3.5 \mathrm{~h}$.

\section{Sampling}

Samples for the identification of protozoa and small metazoa were collected from mixed liquor of the aeration tank in $1 \mathrm{~L}$ plastic bottles during 5 months, two or three times a week. The plastic bottles with mixed liquor samples were half emptied to avoid oxygen limitation and then immediately 
carried to the laboratory. They were kept aerated during the protozoan community inspection and counting.

\section{Identification of microfauna and calculation of SBI}

Protozoa and small metazoa were identified using an optical microscope (magnifications $40 \times$ to $1000 \times$ ) and identification guides when necessary (Canler et al. 1999; Madoni et al. 2005; Foissner et al. 1991; Foissner et al. 1992; Foissner et al. 1994; Foissner et al. 1995). The calculation of the SBI was performed according to the guidelines of Madoni (1994). A sample volume of $25 \mu \mathrm{L}$ from the mixed liquor of the aeration tank was collected in duplicate with an automatic piston-micropipette. Protozoa were identified to genus or species level when necessary, as for example, in the case of the various Vorticella species, which have different indicator values. Protozoa of WWTP can be classified as large and small flagellates (the latter with less than $20 \mu \mathrm{m}$ ), amoebae and, in particularly high numbers, ciliates. Madoni et al. (1993) classified the bacterivorous ciliates in three key groups - free-swimming, crawling and stalked ciliates, according to their feeding and motion behaviors. With the exception of small flagellates, protozoa and metazoa were counted and their abundances presented as ind $/ \mathrm{mL}$. In accordance with the method of Madoni, the small flagellates were not identified with regard to genus or species: they were counted directly in the diagonal of the Fuchs-Rosenthal chamber and their abundances fell in 3 categories: less or equal to 10 , between 10 and 100 , equal or more than 100 . The microscopic observation was performed in the WWTP laboratory ensuring that the period between sampling and finalization of the protozoa and small metazoa identification never surpassed $3 \mathrm{~h}$. This avoids progressive temporal changes in density and richness of the microfauna (Madoni 1994).

The SBI ranges from 0 (indicating the poorest condition) to 10 (indicating the best condition). SBI values are grouped in four classes corresponding to different levels of quality: class I includes SBI values from 8 to 10 (very well colonized and stable sludge, excellent biological activity; very good performance); class II includes 6 and 7 (well colonized and stable sludge, biological activity on decrease; good performance); group III includes 4 and 5 (insufficient biological depuration in the aeration tank; mediocre performance); class IV (poor biological depuration in the aeration tank; low performance) includes the remaining values (Madoni 1994).

\section{Physical-chemical and operational parameters}

Physical and chemical variables were analyzed according to Standard Methods (APHA 1995) in 24-h composed samples: Biological Oxygen Demand in five days $\left(\mathrm{BOD}_{5}\right)$, Chemical Oxygen Demand (COD), and Total Suspended Solids (TSS) from influent, final effluent and aeration tank, Dissolved oxygen (DO), Total Suspended Solids in Mixed
Liquor (MLTSS), Volatile Suspended Solids (VSS) from aeration tank, Sludge Volume Index (SVI), Food to microorganism ratio (F/M) were calculated.

\section{Data analysis}

Experimental data were logarithmically transformed: $x=\ln (x+1)$. Statistical analyses were performed by Statistic 7.0 based on the calculation of Pearson and Kendall correlation coefficients for the parameters following normal and non-normal distributions, respectively. Nineteen physical-chemical and operational parameters were selected for statistical analysis: TSS, DO, SVI and F/M from mixed liquor, TSS, COD and $\mathrm{BOD}_{5}$ removal and TSS, COD and $\mathrm{BOD}_{5}$ from influent, final effluent and mixed liquor. Correlation coefficients were determined in order to examine potential relationships between protozoan and small metazoan taxa and the physical-chemical and the performance parameters.

\section{Results}

The minimum, maximum and mean values of each parameter during the study period are shown in Table 1 . The values presented as values of the final effluent are those relating to samples taken after the first settler and before entering the percolating step so that the activated-sludge step could be studied without interference of subsequent treatment stages. Since nutrient levels of ammonia, nitrate, nitrogen, and phosphorus were measured only monthly, they were not correlated to the other variables.

In the 35 samples collected over the five-months' period, 30 taxa of protozoa and small metazoa were identified, 14 out of which being bacterivorous ciliates (crawling, attached and free-swimming), 4 testate amoebae, 4 large flagellates, 6 carnivorous ciliates and 2 small metazoa (Table 2). As stated before, small flagellates were counted but not identified.

Table 3 shows the total abundance of protozoa and small metazoa, the key groups defined by Madoni (1994) and the five taxa considered of particular importance, either because they were the most abundant or frequent (Epistylis rotans, Aspidisca cicada, Arcella sp.), because of their recognized value as bio-indicators of degrading conditions in the aeration tank of activated sludge (Opercularia spp.) or because both these criteria were taking effect here (Vorticella microstoma). Considering the maximum density value attained, the key groups can be ranged by this order: attached ciliates $>$ crawling ciliates $>$ testate amoebae $>$ free-swimming ciliates, being carnivorous ciliates, and small metazoa even less abundant.

The SBI was used to assess the state of the community (Fig. 1). Between March and April, the SBI values were around 9 and 10, corresponding to Class of Treatment Quality I (well colonized and stable sludge with optimal biological 
Table 1. Physical and chemical variables in the studied WWTP.

\begin{tabular}{|c|c|c|c|c|c|}
\hline & & Maximum & Minimum & Average & Standard deviation \\
\hline Sewage & COD (mg/L) & 1647 & 400 & 673 & 238 \\
\hline (entrance of the & $\mathrm{BOD}_{5}(\mathrm{mg} / \mathrm{L})$ & 780 & 110 & 332 & 140 \\
\hline \multirow[t]{5}{*}{ WWTP) } & TSS (mg/L) & 2367 & 107 & 421 & 414 \\
\hline & $\mathrm{N}(\mathrm{mg} / \mathrm{L})$ & 39 & 16 & 22.4 & 9.6 \\
\hline & $\mathrm{NH}_{4}{ }^{+}(\mathrm{mg} / \mathrm{L})$ & 19 & 11 & 15 & 3.8 \\
\hline & $\mathrm{NO}_{3}{ }^{-}(\mathrm{mg} / \mathrm{L})$ & 3 & 0.6 & 1.9 & 1.3 \\
\hline & $\mathrm{P}(\mathrm{mg} / \mathrm{L})$ & 16 & 5 & 8.8 & 4.9 \\
\hline Final effluent & $\mathrm{COD}(\mathrm{mg} / \mathrm{L})$ & 141 & 64 & 109 & 17 \\
\hline (end of the & $\mathrm{BOD}_{5}(\mathrm{mg} / \mathrm{L})$ & 29 & 12 & 19 & 5 \\
\hline activated sludge & TSS (mg/L) & 62 & 12 & 28 & 10 \\
\hline \multirow[t]{4}{*}{ step) } & $\mathrm{N}(\mathrm{mg} / \mathrm{L})$ & 13 & 7 & 8.4 & 2.6 \\
\hline & $\mathrm{NH}_{4}^{+}(\mathrm{mg} / \mathrm{L})$ & 8 & 2 & 4.2 & 2.4 \\
\hline & $\mathrm{NO}_{3}{ }^{-}(\mathrm{mg} / \mathrm{L})$ & 0.4 & 0.2 & 0.3 & 0.1 \\
\hline & $\mathrm{P}(\mathrm{mg} / \mathrm{L})$ & 7 & 3 & 5 & 1.6 \\
\hline \multirow[t]{7}{*}{ Removal Ratio } & COD & 91 & 68 & 82 & 6 \\
\hline & $\mathrm{BOD}_{5}$ & 98 & 77 & 93 & 4 \\
\hline & TSS & 99 & 48 & 89 & 9 \\
\hline & $\mathrm{N}(\mathrm{mg} / \mathrm{L})$ & 79 & 35 & 59.4 & 17.3 \\
\hline & $\mathrm{NH}_{4}^{+}(\mathrm{mg} / \mathrm{L})$ & 88 & 50 & 72.2 & 13.9 \\
\hline & $\mathrm{NO}_{3}{ }^{-}(\mathrm{mg} / \mathrm{L})$ & 87 & 66 & 78.8 & 10.2 \\
\hline & $\mathrm{P}(\mathrm{mg} / \mathrm{L})$ & 56 & 31 & 38.5 & 11.9 \\
\hline \multirow[t]{4}{*}{ Mixed liquor } & $\mathrm{DO}(\mathrm{mg} / \mathrm{L})$ & 2 & 0.6 & 1.3 & 0.3 \\
\hline & MLTSS (mg/L) & 8100 & 3300 & 5678 & 1377 \\
\hline & $\mathrm{SVI}(\mathrm{ml} / \mathrm{g})$ & 132 & 61 & 104 & 18 \\
\hline & $\mathrm{F} / \mathrm{M}\left(\mathrm{kg} \mathrm{BOD} / \mathrm{kg} \mathrm{VSS}^{*} \mathrm{~d}\right)$ & 1.4 & 0.1 & 0.4 & 0.3 \\
\hline
\end{tabular}

activity and a high depurating efficiency). The high SBI values during this period were due to a high number of species; co-dominance of crawling ciliates, attached ciliates and testate amoebae, and low numbers of small flagellates. In May, the SBI values were mainly 8 with the exception of a value 6 corresponding to the last day of sampling in May.
These values of 8 correspond to Class I and the remaining value of 6 corresponds to Class II (stable and well colonized sludge with sub-optimal activity and a sufficient purifying efficiency). The SBI values decreased in this period, because the abundance of crawling ciliates was strongly reduced. From the beginning of June, there was a period of instability:

Table 2. Protozoa and small metazoa identified in the studied WWTP.

Taxonomic identification

\begin{tabular}{llll}
\hline Crawling ciliates & Attached ciliates & Free-swimming ciliates & Testate amoebae \\
\hline Aspidisca cicada & Zoothamnium $\mathrm{sp}$. & Tetrahymena pyriformis & Difflugia $\mathrm{sp}$. \\
Aspidisca lynceus & Carchesium sp. & Uronema nigricans & Arcella sp. \\
Acineria uncinata & Vorticella aquadulcis & Centropyxis sp. \\
Chilodonella uncinata & Vorticella microstoma & Euglypha sp. \\
& Vorticella convallaria & & \\
& Epistylis rotans & & \\
& Epistylis plicatilis & & \\
& Opercularia spp. & &
\end{tabular}

Flagellates $(>20 \mu \mathrm{m})$

Flagellate 1

Flagellate 2

Peranema sp.

Euglena sp.
Carnivorous

Small metazoa

Litonotus sp.

Suctoria 1

Rotaria sp.

Nematode

Acineta sp.

Podophrya sp.

Tokophrya sp.

Prorodon sp. 
Table 3. Main biological parameters in the studied WWTP.

\begin{tabular}{|c|c|c|c|c|c|}
\hline & \multirow[t]{2}{*}{ Frequency $(\%)$} & \multicolumn{4}{|c|}{ Abundance (ind/mL) ${ }^{\mathrm{a}}$} \\
\hline & & Maximum & Minimum & Average & Standard deviation \\
\hline Free-swimming ciliates & 14 & 40 & 0 & 3 & 9 \\
\hline Crawling ciliates & 63 & 2439 & 0 & 432 & 722 \\
\hline Attached ciliates & 100 & 4382 & 80 & 1194 & 1023 \\
\hline Testate amoebae & 97 & 740 & 0 & 228 & 179 \\
\hline Small flagellates & 100 & 25 & 1 & 4 & 5 \\
\hline Opercularia spp. & 51 & 160 & 0 & 31 & 42 \\
\hline Vorticella microstoma & 77 & 719 & 0 & 105 & 159 \\
\hline Aspidisca cicada & 43 & 1780 & 0 & 311 & 550 \\
\hline Arcella sp. & 94 & 640 & 0 & 175 & 164 \\
\hline Espistylis rotans & 100 & 3420 & 20 & 830 & 846 \\
\hline Abundance & - & 6600 & 400 & 2023 & 1666 \\
\hline Number of taxa & - & 18 & 6 & 10 & 3 \\
\hline
\end{tabular}

${ }^{\mathrm{a}}$ With the exception of the small flagellates corresponding to direct counting in the diagonal of the Fuchs-Rosenthal Camera.

SBI values ranged between 4 and 10, the former corresponding to Class III (insufficient biological activity and a mediocre purifying efficiency). Despite the instability observed, the WWTP was further characterized by SBI values ranging between 6 and 9 by the end of the sampling period (July). The SBI average value over the five-month study was 8 with a standard deviation of 2 .

Changes observed in the protozoan community structure are depicted in Fig. 2. During the five months of the study, attached ciliates were the dominant group. Crawling ciliates almost disappeared after the first six weeks of sampling. Testate amoebae were more abundant in April and May and in the middle of July. The presence of carnivorous ciliates and small metazoa (presented as "others"), though varying during the study period, was more perceptible from April. Abundances of attached ciliates above $80 \%$ were observed in the end of May, in the second half of June and in the middle of July.

In order to study the relationships between the physical-chemical and operational parameters and the biological parameters, correlations were calculated by using the Pearson and Kendall correlation coefficients (Table 4).

We did not find significant correlations between any taxa and the quality of the final effluent $\left(\mathrm{BOD}_{5}\right.$ or COD). However, two significant positive correlations were determined between the $\mathrm{BOD}_{5}$ of the final effluent and the amount of small flagellates and the protozoan diversity; the first with a probability higher than $95 \%$ and the latter with a probability higher than 99\%. The Total Suspended Solids (TSS) of the effluent correlated positively with the SBI, the abundance and diversity of the microfauna, the abundance of testate amoeba (and Arcella sp.), crawling ciliates (and Aspidisca cicada) and attached ciliates. The effluent TSS was significantly negatively correlated to Vorticella microstoma. Regarding the quality of the treatment, no correlations were significant between the biological parameters and the removal ratios of $\mathrm{BOD}_{5}$, COD or TSS (data not shown).

The influent COD exhibited three significant negative correlations with biological parameters, namely with testate

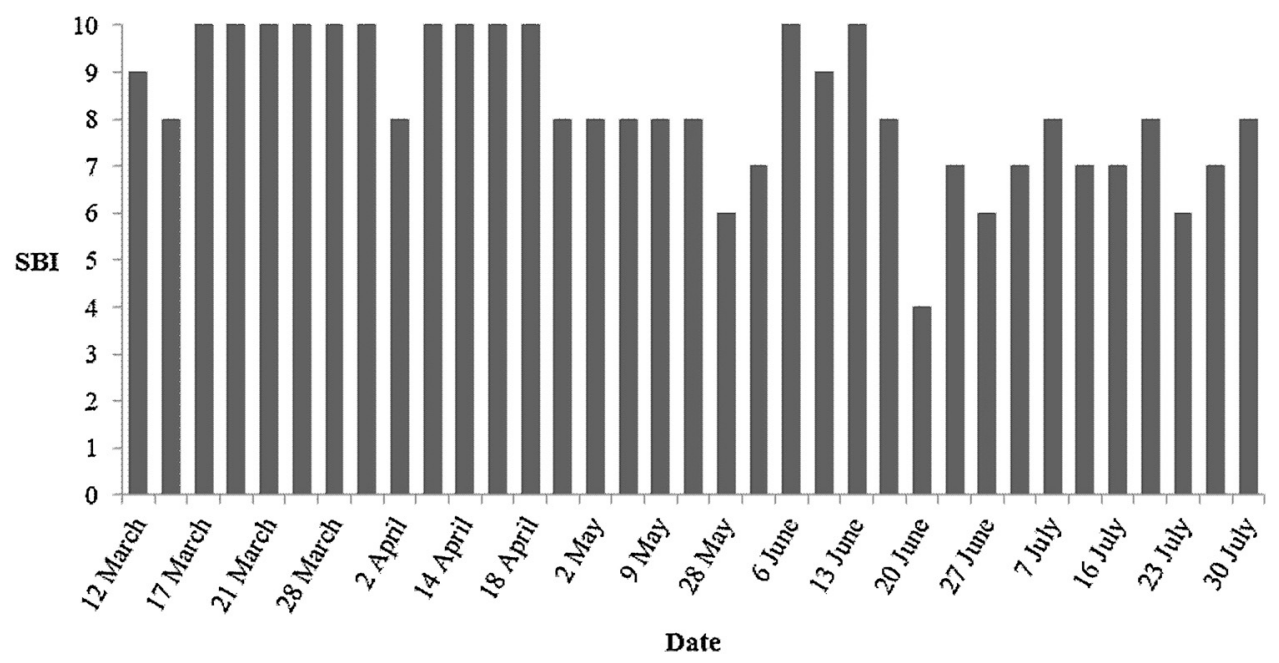

Fig. 1. Variation of the Sludge Biotic Index (SBI) during the period of study. 


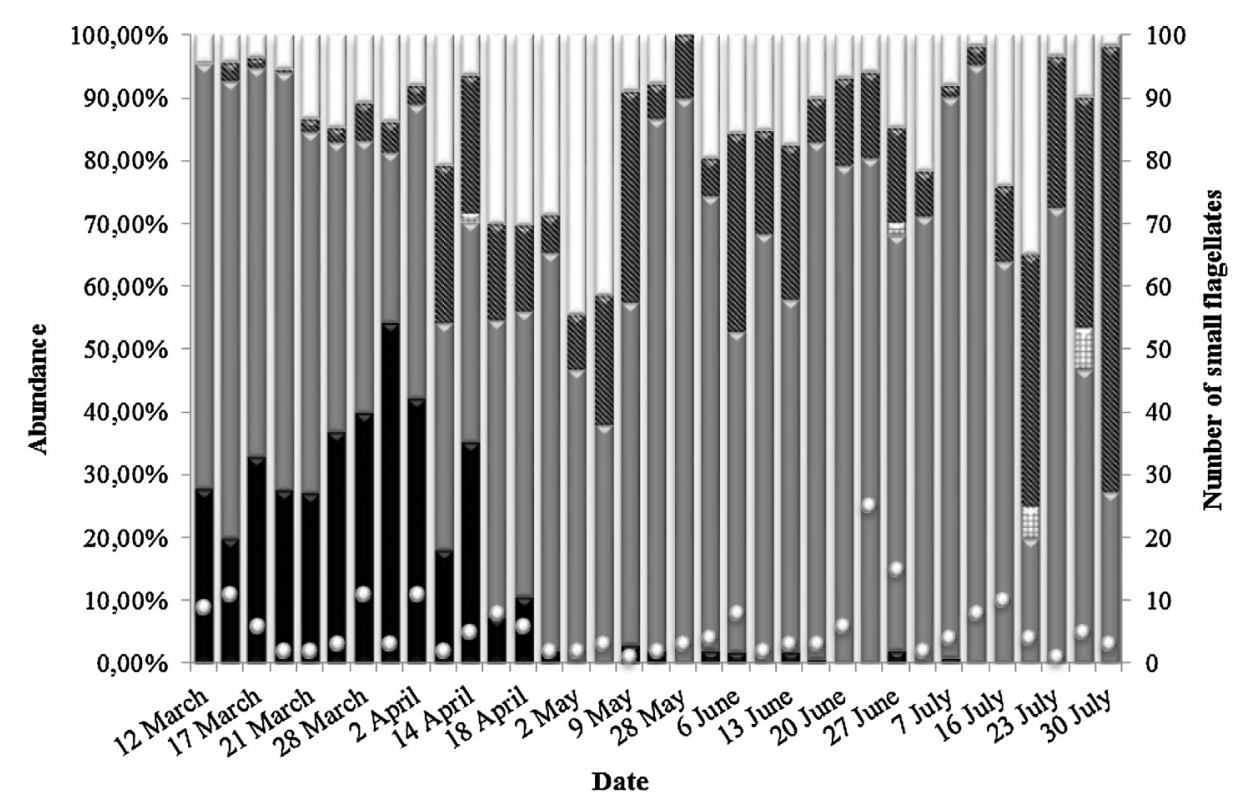

घCrawling ciliates $₫$ Attached ciliates $\boxminus$ Free-swimming ciliates $₫$ Others $\sqcup$ Testate amoebae OSmall flagellates

Fig. 2. Distribution of the microfauna key groups during the period of study (small flagellates are presented as the average number on the diagonal of the Fuchs-Rosenthal Camera).

amoebae $(-0.38 ; n=33)$, Arcella sp. $(-0.36 ; n=33)$ and Aspidisca cicada $(-0.36 ; n=33)$. The influent $\mathrm{BOD}_{5}$ showed an inverse relation with Aspidisca cicada $(-0.37 ; n=29)$ and a positive correlation with Opercularia spp. $(0.60 ; n=29)$ and Vorticella microstoma $(0.63 ; n=29)$. The solids in the entrance of the activated sludge system revealed merely two negative significant correlations, namely with the number of protozoan and small metazoan diversity $(-0.37 ; n=30)$ and with the SBI $(-0.50 ; n=30)$.

With reference to the characteristics of the mixed liquor, significant correlations were established between Aspidisca cicada and DO in mixed liquor $(0.79 ; n=35)$ : as the oxygen in the aeration tank decreased, the number of $A$. cicada decreased also. The same tendency was observed for the

Table 4. Statistical analysis of physical-chemical/operational and biological parameters (Pearson and Kendall correlation coefficients).

\begin{tabular}{|c|c|c|c|c|c|c|c|c|c|c|}
\hline \multirow[t]{3}{*}{ Biological parameters } & \multicolumn{10}{|c|}{ Physical/chemical and operational parameters } \\
\hline & \multicolumn{3}{|l|}{ Influent } & \multicolumn{3}{|c|}{ Effluent } & \multicolumn{3}{|c|}{ Mixed liquor } & \multirow[b]{2}{*}{$\mathrm{F} / \mathrm{M}$} \\
\hline & COD & $\mathrm{BOD}_{5}$ & TSS & COD & $\mathrm{BOD}_{5}$ & TSS & DO & MLTSS & SVI & \\
\hline Number of samples $n=$ & 33 & 29 & 30 & 22 & 30 & 31 & 35 & 35 & 35 & 27 \\
\hline Free-swimming ciliates & 0.14 & -0.02 & -0.02 & -0.02 & 0.01 & -0.13 & 0.04 & -0.33 & $0.36^{*}$ & 0.07 \\
\hline Crawling ciliates & -0.30 & -0.08 & -0.31 & -0.17 & 0.17 & $0.73^{* * *}$ & $0.62^{* * * *}$ & $0.77^{* * * *}$ & -0.22 & $-0.51^{* *}$ \\
\hline Attached ciliates & $-\underline{0.25}$ & $\underline{0.14}$ & 0.08 & $-\underline{0.17}$ & $\underline{0.04}$ & $0.39^{*}$ & 0.30 & $\underline{0.36}^{*}$ & $-\underline{0.03}$ & -0.11 \\
\hline Testate amoebae & $-\overline{\mathbf{0 . 3 8}}{ }^{*}$ & $-\overline{0.10}$ & -0.19 & $-\overline{0.14}$ & 0.03 & $\mathbf{0 . 5 3}^{* *}$ & $0.43^{* *}$ & $\overline{0.60}^{* * * *}$ & $-\overline{0.29}$ & -0.38 \\
\hline Small flagellates & $-\underline{0.05}$ & $\underline{0.03}$ & 0.15 & $-\underline{0.20}$ & $\underline{0.43}^{*}$ & 0.21 & 0.24 & $-\underline{0.21}$ & $\underline{0.17}$ & 0.18 \\
\hline Opercullaria spp. & $\overline{0.04}$ & $\overline{0.60}^{* * * *}$ & -0.32 & $\overline{0.03}$ & $\overline{0.21}$ & -0.08 & -0.23 & $\overline{0.01}$ & $\overline{0.06}$ & 0.19 \\
\hline Vorticella microstoma & 0.15 & $\mathbf{0 . 6 3} 3^{* * * *}$ & -0.01 & -0.21 & 0.21 & $-0.37^{*}$ & $-0.51^{* *}$ & -0.09 & -0.02 & $0.46^{*}$ \\
\hline Aspidisca cicada & $-0.36^{*}$ & $-0.37^{*}$ & 0.20 & -0.20 & 0.05 & $0.71^{* * * *}$ & $0.79^{* * *}$ & $0.75^{* * *}$ & -0.26 & $-0.58^{* *}$ \\
\hline Arcella sp. & $-0.36^{*}$ & -0.22 & -0.21 & -0.21 & -0.06 & $0.52^{* *}$ & $0.44^{* *}$ & $0.58^{* * * *}$ & -0.22 & $-0.46^{* *}$ \\
\hline Espistylis rotans & $-\underline{0.23}$ & $\underline{0.09}$ & 0.10 & $-\underline{0.13}$ & $\underline{0.04}$ & 0.35 & 0.33 & $\underline{0.18}$ & $\underline{0.10}$ & -0.09 \\
\hline SBI & $-\overline{0.24}$ & $-\overline{0.15}$ & $-\mathbf{0 . 5 0} 0^{* *}$ & $\overline{0.06}$ & $\overline{0.09}$ & $0.48^{* *}$ & $0.52^{* *}$ & $\overline{\mathbf{0 . 6 6}}^{* * *}$ & $-\overline{0.25}$ & -0.47 \\
\hline Abundance & $-\underline{0.29}$ & $\underline{0.03}$ & -0.17 & $-\underline{0.17}$ & 0.10 & $\mathbf{0 . 5 3} 3^{* *}$ & $0.51^{* *}$ & $0.52^{* *}$ & 0.01 & -0.28 \\
\hline Diversity & $-\overline{0.23}$ & $\overline{0.01}$ & $-0.37^{*}$ & $-\overline{0.19}$ & $0.49 *$ & $0.60^{* * * *}$ & $0.52^{* *}$ & $\overline{0.65}^{* * *}$ & $-\overline{0.05}$ & -0.30 \\
\hline
\end{tabular}

The bold numbers are the significant correlations, either positive and negative.

*** $P<0.001$.

** $P<0.01$.

${ }^{*} P<0.05$.

Underlined - Pearson correlation.

Not underlined - Kendall correlation. 
Table 5. Correlations between some of the most significant taxa of protozoa in the Barcelos WWTP (Kendall correlation) (number of samples $=35$ ).

\begin{tabular}{|c|c|c|c|c|}
\hline & Vorticella microstoma & Arcella sp. & Aspidisca cicada & Epistylis rotans \\
\hline Opercularia spp. & $0.41^{*}$ & -0.001 & -0.27 & $-0.39^{*}$ \\
\hline Vorticella microstoma & & -0.21 & $-0.43^{* *}$ & $-0.43^{*}$ \\
\hline Arcella sp. & & & $0.38^{*}$ & 0.16 \\
\hline Aspidisca cicada & & & & $0.50^{*}$ \\
\hline
\end{tabular}

The bold numbers are the significant correlations, either positive and negative.

**** $P<0.001$.

** $P<0.01$.

${ }^{*} P<0.05$.

testate amoeba and Arcella sp., the overall abundance and diversity and, finally, the SBI. In contrast, the correlation between Vorticella microstoma and the DO was significant but negative.

It is also obvious from Table 4 that MLTSS presented various positive associations with biological parameters, such as Aspidisca cicada (and, consequently, with crawling ciliates), attached ciliates, Arcella sp. (and, consequently, with testate amoebae), overall abundance and diversity of the protozoa and, finally, with the SBI. In fact, in the presence of low concentrations of MLTSS, we observed decreases in the number of Aspidisca cicada, crawling and attached ciliates, testate amoebae and Arcella sp., as well as in the number and diversity of protozoa and in the value of the SBI.

Crawling ciliates (and, consequently, Aspidisca cicada) and Arcella sp. demonstrated a significant negative association with the $\mathrm{F} / \mathrm{M}$ ratio (respectively $-0.51,-0.58$ and $-0.46 ; n=27)$, which, on the contrary, showed a significant positive correlation with Vorticella microstoma $(0.46 ; n=27)$.

The free-swimming ciliates revealed a significant positive correlation with the SVI $(0.36 ; n=35)$.

Further, correlations among biological parameters based on the Kendall correlation coefficient were established (Table 5). The correlations showed some associations between the protozoa selected for this study: the presence of Opercularia spp. was accompanied by the presence of Vorticella microstoma. Opercularia spp. showed a significant negative correlation with Epistylis rotans $(-0.39 ; n=35)$. Moreover, Epistylis rotans presented a significant negative correlation with Vorticella microstoma $(-0.35 ; n=35)$ and displayed a significant positive relationship with the crawling ciliate Aspidisca cicada (0.51). Aspidisca cicada, in addition, was negatively correlated with Vorticella microstoma $(-0.48$, $n=35$ ) and showed a strongly positive relation to Arcella sp. $(0.61 ; n=35)$.

\section{Discussion}

Among the 30 taxa identified during the studied period (Table 2), three of the most frequent have an established value as biological indicators (Madoni 1994; Madoni et al. 2005): Epistylis rotans (100\% of the samples) indicates a good quality of the water treated by the WWTP. Arcella sp. $(94 \%)$ is frequently associated with good oxygenation, extended aeration and good nitrification. Vorticella microstoma $(77 \%)$ is an indicator of insufficient oxygenation and high load. Aspidisca cicada $(43 \%)$ is often related to adequate performance, but some authors have also related its presence with toxic inputs (Abraham et al. 1997; Nicolau et al. 2005). Opercularia spp. (51\%) is known to be prevailing in aerating tanks with degrading conditions and poor performance.

The SBI, whose results are shown in Fig. 1, is considered a good indicator of the health state of the community of protozoa and small metazoa (Madoni 1994). The evolution of the SBI during the studied period was in general accordance with the physical-chemical assessment of the performance of this WWTP: a period of good performances was followed by a period of instable operation with subsequent problems in the quality of the final effluent (sample individual data not shown due to confidential agreement with the WWTP administration board). The sample with an SBI value of 4 , the only sample with a value corresponding to class III, corresponded to a situation of particular mal-functioning of the WWTP. Also, the SBI seemed to reflect the general performance of the plant as perceived by the technicians and manager. Nevertheless, the SBI did not show any of the expected correlations either with the removal ratios or with the quality of the effluent (Table 4). The significant positive correlations with the DO levels and the MLTSS obtained in the present study were also found by Madoni (1994), but the negative significant correlation with the influent TSS or the significant positive correlation with the effluent TSS are not reported in other studies.

Changes observed in the protozoan community structure (Fig. 2) reflected some of the other parameters. As referred to, crawling ciliates almost disappeared after the first six weeks of sampling, which corresponds to the period when SBI values were consistently 10 , with the exception of three samples. Considering the accepted indicator value of testate amoeba, Arcella sp. in particular (Madoni 1994; Madoni et al. 2005), it was unexpected that Arcella sp. predominated throughout the periods of instability. Higher values of amoeba abundance always corresponded to higher values of the SBI. Although more evident from April, the abundance of carnivorous ciliates was inconstant and does neither seem to have corresponded to any particular condition of operation, nor to 
have reflected any SBI condition. The attached ciliates dominated the samples throughout the studied period but surpassed the $80 \%$ only occasionally. Abundances of attached ciliates above $80 \%$ corresponded, as expected, to lower values of the SBI and to general lower performances of the WWTP, namely when experiencing transient phenomena of malfunctioning (Madoni 1994).

We did not find significant relationships between specific taxa and the quality of the effluent in terms of $\mathrm{BOD}_{5}$ or COD (Table 4) corroborating the findings of Dubber and Gray (2011a). Inversely, Curds and Cockburn (1970) and Salvadó et al. (1995) observed that Vorticella microstoma and Opercularia spp. were dominant when the quality of the effluent decreased and suggested their use as bio-indicators of this. Perhaps, due to the high content of solids in the effluent after the activated sludge step, filtered BOD and COD should have been determined and studied for correlation purposes. Correlations were found between the effluent $\mathrm{BOD}_{5}$ and the small flagellates $(0.43 ; n=30)$ and the diversity of the community $(0.49 ; n=30)$. The first correlation was expected in the form of the presence of small flagellates associated to a bad performance of the biological depuration (Madoni 1994). On the contrary, the positive correlation between the effluent $\mathrm{BOD}_{5}$ and diversity was not forecasted as diversity was expected to decrease with lowering performance. Regarding the quality of the influent, the significant correlations obtained between the influent $\mathrm{BOD}_{5}$ and Aspidisca cicada (negative), Opercularia sp. and Vorticella microstoma (positive) are in accordance with the general knowledge about these taxa. No correlations were found between the biological parameters and the removal ratios of $\mathrm{BOD}_{5}, \mathrm{COD}$ or TSS which means that they were no indicators of treatment quality.

The Total Suspended Solids (TSS) of the effluent showed the highest number of correlations with the biological parameters, positively with the SBI, the abundance and the diversity of the microfauna, the abundance of testate amoeba (and Arcella sp.), crawling ciliates (and Aspidisca cicada) and attached ciliates, and negatively with the abundance of Vorticella microstoma $(-0.37 ; n=31)$. Considering the indicator value of the referred biological parameters (Madoni 1994; Madoni et al. 2005) and the fact that higher effluent TSS reflects a lower performance of the plant, we expected opposite correlations.

Crawling ciliates (and, consequently, Aspidisca cicada) demonstrated a significant negative association with the F/M ratio, which can be associated with the possible metabolic advantage in competing for substrate (Lee et al. 2004). The significant positive correlation established with Vorticella microstoma was expected because the species is mentioned to be, in general, resistant to increased organic load (Madoni 1994). F/M and Arcella sp. showed a negative correlation. Arcella $s p$. is more abundant or even dominant in sludges characterized by low loading (Chierici and Madoni 1991).

The positive correlation between the DO and the abundance of Aspidisca cicada contradicts the findings of Cingolani et al. (1992), Cingolani and Ciccarelli (1997),
Nicolau et al. (2005, 2007) and Dubber and Gray (2011a) who stated that Aspidisca cicada showed a remarkable ability to survive in adverse conditions. The crawling ciliates, as a group, also showed a significant positive association with the DO of the mixed liquor $(0.62 ; n=35)$, and Vorticella microstoma indicated the lack of DO with a significant coefficient value of $-0.51(n=35)$ which can be explained by its good resistance to the influence of anoxic environment and environmental changes (Madoni 1994; Esteban et al. 1991; Lee et al. 2004; Dubber and Gray 2011b). Testate amoebae and Arcella sp. also demonstrated to have a positive association with DO (respectively 0.43 and $0.44 ; n=35$ ), confirming that they can be a good indicator of high DO levels in the aeration tank (Chierici and Madoni 1991). Significant positive correlations were achieved between concentrations of DO in the mixed liquor and the overall abundance, the overall diversity and the SBI values (0.51, 0.52 and 0.52 , respectively; $n=35$ ). The results suggest that high DO levels increase the number and the diversity of protozoa and small metazoa in the mixed liquor and, consequently, the value of SBI once this index is based on the abundance and species diversity of the community prevailing in the system (Madoni 1994).

The significant positive correlation between the SVI and the free-swimming ciliates corroborate the findings of Liu et al. (2008) and Martín-Cereceda et al. (1996), which found swimming ciliates dominant when lower sludge quality was detected, and concluded that this group of ciliated protozoa could be a good indicator of bad settlement conditions of sludge. In contrast, Zhou et al. (2006, 2008) found a significant negative correlation between testate amoebae and SVI.

The correlations found between the most frequent taxa (in Table 5) were as expected (Madoni 1994). The positive association of Epistylis rotans and Aspidisca cicada was also observed by Zhou et al. (2006). In summary, Epistylis rotans, Arcella sp. and Aspidisca cicada appear in one group associated with overall good conditions for depuration, while Vorticella microstoma and Opercularia sp. appear opposite to the previous and are associated with bad conditions of depuration in the plant (Madoni 1994; Salvadó et al. 1995).

In recent years, several studies have considered the SBI to be a useful monitoring tool that can successfully evaluate the health of the activated sludge. Papadimitriou et al. (2007) stated that the application of the SBI could be limited upon the addition of toxic influent, especially in cases of co-treatment of municipal and industrial wastewaters. The textile sewage has oils/fats/waxes removed by scouring, a number of surfactants present along with salts, dyes, a range of compounds from simple inorganic to complex organic compounds and heavy metals (Moran et al. 1997). These compounds can be highly toxic to the protozoan and metazoan communities. Drzewicki and Kulikowska (2011) mentioned that the occurrence of high SBI values at a low effluent quality limits the usefulness of the SBI for monitoring the status of an activated sludge system and the effluent quality in municipal WWTP treating wastewater from septic tanks. In this study, the SBI 
did not reflect the performance of the WWTP in terms of TSS, COD or BOD removal. Nevertheless, it was considered an indicator of the environmental conditions of the aerating tank in terms of DO and MLTSS and the overall state of the community. Also, it revealed the global functioning as evaluated by the technicians and the manager of the plant.

\section{Conclusions}

Based upon the statistical correlations that we obtained, the usefulness of the SBI may be limited for monitoring the status of an activated sludge system and the effluent quality of wastewater treated by municipal WWTP with non-conventional designs. The temporal variation of the SBI overall reflected the general performance of the plant and closely reflected the state of the community. It correlated significantly with influent TSS, MLTSS and DO, but not with effluent $\mathrm{COD}$ or $\mathrm{BOD}_{5}$, as expected. This discrepancy can be due to the fact that total COD and BOD were determined instead of the soluble COD and BOD.

The first remarkable and unexpected result was the fact that no correlation could be established between biological parameters and removal of $\mathrm{BOD}_{5}$, COD or TSS in the plant. Also in this case, the determination of soluble COD and BOD could lead to different results. However, statistical analysis showed that several groups of protozoa, including the key groups defined by Madoni (1994), significantly correlated with physical-chemical and operational parameters in the studied WWTP. Several significant correlations were established between the biological parameters and the characteristics of the mixed liquor, especially the DO and MLTSS, most of them corroborating the premises that Madoni made to conceive the SBI. Vorticella microstoma was, as expected, an indicator of high $\mathrm{F} / \mathrm{M}$ and influent $\mathrm{BOD}_{5}$, and of low levels of DO in the aerated tank. Aspidisca cicada indicated low F/M and COD and $\mathrm{BOD}_{5}$ of the influent, and Arcella sp. was closely related to low F/M and influent COD and high values of DO and MLTSS in the aerated tank. Nevertheless, no specific taxa proved to be an appropriate bio-indicator of the effluent quality with the exception of the number of the small flagellates. Contradicting results of other studies, Aspidisca cicada served as an indicator of good conditions for depuration. Probable toxicity of the influent has not biased the conclusions.

A high number of biological parameters ( 9 parameters, the highest number) were positively correlated with the TSS of the effluent, all of them in contradiction with published data and general knowledge of these systems.

Free-swimming ciliates were the only group that significantly correlated with the settling ability: as the SVI rised, the number of free-swimming ciliates increased also, which is in accordance with the works of other authors that refer to its relation with generally lower performances of the WWTP or bad quality of the final effluent (Liu et al. 2008; Madoni 1994; Madoni et al. 2005; Martín-Cereceda et al. 1996).
The determinations of the key groups and some species (e.g., the crawling ciliate Aspidisca cicada and the attached ciliate Vorticella microstoma) along with general community parameters (e.g., the abundance and diversity) provided important information to optimize the activated sludge system as well as to identify causes and solution approaches of operational problems during the period of the study, especially as far as DO and F/M were concerned.

\section{Acknowledgements}

The authors gratefully acknowledge Carla Sá Carneiro and Joana Silva from Ecobarcelos, A.C.E. The financial support from the Portuguese Foundation for Science and Technology (FCT) and European Community fund FEDER, trough Program COMPETE, in the ambit of the Project FCOMP-01-0124-FEDER-007025 (PTDC/AMB/68393/2006) is gratefully acknowledged. The authors also thank the FCT Strategic Project PEst-OE/EQB/LA0023/2013, the FCT Project RECI/BBBEBI/0179/2012 (FCOMP-01-0124-FEDER-027462) and the Project "BioEnv - Biotechnology and Bioengineering for a sustainable world", REF. NORTE-07-0124-FEDER-000048, co-funded by the Programa Operacional Regional do Norte (ON.2 - O Novo Norte), QREN, FEDER.

\section{References}

Abraham, J.V., Butler, R.D., Sigee, D.C., 1997. Ciliate populations and metals in an activated-sludge plant. Water Res. 31, 1103-1111.

Al-Shahwani, S.M., Horan, N.J., 1991. The use of protozoa to indicate changes in the performance of activated sludge plants. Water Res. 25, 633-638.

Arévalo, J., Moreno, B., Pérez, J., Gómez, M.A., 2009. Applicability of the Sludge Biotic Index (SBI) for MBR activated sludge control. J. Hazard. Mater. 167, 784-789.

Canler, J.P., Perret, J.M., Duchène, P., Cotteux, É., 1999. Aide au diagnostic des stations d'épuration par l'observation microscopique des boues actives. Cemagref Éditions, France.

Chierici, E., Madoni, P., 1991. Comparative analysis of the activated microfauna in small municipal plants. In: Madoni, P. (Ed.), Biological Approach to Sewage Treatment Process: Current Status and Perspectives. Centro Bazzucchi, Perugia, pp. 83-87.

Cingolani, L., Ciccarelli, E., 1997. Microscopic investigations on thirty-nine activated sludge plants in Umbria. Evaluation of Sludge Biotic Index reliability. In: Proceedings of the Second International Conference on the Microrganisms in Activated Sludge and Biofilm Processes, 21-23 July, Berkeley, CA, pp. 527-529.

Cingolani, L., Cossignani, M., Miliani, R., 1992. Relationships between population dynamics and operating parameters in an activated sludge-plant by statistical analysis. Water Sci. Technol. 25, 299-400.

Curds, C.R., Cockburn, A., 1970. Protozoa in biological sewagetreatment processes. II. Protozoa as indicators in the activatedsludge process. Water Res. 4, 203-249. 
Drzewicki, A., Kulikowska, D., 2011. Limitation of Sludge Biotic Index application for control of a wastewater treatment plant working with shock organic and ammonium loadings. Eur. J. Protistol. 47, 287-294.

Dubber, D., Gray, N.F., 2011a. The influence of fundamental design parameters on ciliates community structure in Irish activated sludge systems. Eur. J. Protistol. 47, 274-286.

Dubber, D., Gray, N.F., 2011b. The effect of anoxia and anaerobia on ciliate community in biological nutrient removal systems using laboratory-scale sequencing batch reactors (SBRs). Water Res. 45, 2213-2226.

Esteban, G., Tellez, C., Bautista, L.M., 1991. Dynamics of ciliated protozoa communities in the activated-sludge process. Water Res. 2, 967-972.

Foissner, W., Berger, H., Kohman, F., 1992. Taxonomische und Ökologische Revision der Ciliaten des Saprobiensystems. Band II: Peritrichia, Heterotrichida, Odontostomatida (Taxonomic and ecologic revision of the ciliates of the saprobic system. Volume II: Peritrichia, Heterotrichida, Odontostomatida). Bavarian State Office for Water Management, Germany.

Foissner, W., Berger, H., Kohman, F., 1994. Taxonomische und Ökologische Revision der Ciliaten des Saprobiensystems. Band III: Prostomatida, Nassulida (Taxonomic and ecologic revision of the ciliates of the saprobic system. Volume III: Prostomatida, Nassulida). Bavarian State Office for Water Management, Germany.

Foissner, W., Blatterer, H., Berger, H., Kohman, F., 1991. Taxonomische und Ökologische Revision der Ciliaten des Saprobiensystems. Band I: Cyrtophorida, Oligothrichida, Hypotrichia, Colpodea (Taxonomic and ecologic revision of the ciliates of the saprobic system. Volume I: Cyrtophorida, Oligothrichida, Hypotrichia, Colpodea). Bavarian State Office for Water Management, Germany.

Foissner, W., Blatterer, H., Berger, H., Kohman, F., 1995. Taxonomische und Ökologische Revision der Ciliaten des Saprobiensystems. Band IV: Gymnostomatea, Loxodes, Suctoria (Taxonomic and ecologic revision of the ciliates of the saprobic system. Volume IV: Gymnostomatea, Loxodes, Suctoria). Bavarian State Office for Water Management, Germany.

Fried, J., Mayr, G., Berger, H., Traunspurger, W., Psenner, R., Lenner, H., 2000. Monitoring protozoa and metazoa biofilm communities for assessing wastewater quality impact and reactor up-scaling effect. Water Sci. Technol. 41, 309-316.

Holenda, B., Domokons, E., Rédey, Á., Fazakas, J., 2008. Dissolved oxygen control of the activated sludge wastewater treatment process using model predictive control. Comput. Chem. Eng. 32, 1270-1278.

Hu, B., Qi, R., Yang, M., 2013a. Systematic analysis of microfauna indicator values for treatment performance in a full-scale municipal wastewater treatment plant. J. Environ. Sci. 25, 1379-1385.

Hu, B., Qi, R., An, W., Xu, M., Zhang, Y., Bai, X., Bao, H., Wen, Y., Gu, J., Yang, M., 2013b. Dynamics of the microfauna community in a full-scale municipal wastewater treatment plant experiencing sludge bulking. Eur. J. Protistol. 49, 491-499.

Lee, S., Basu, S., Tyler, C.W., Wei, I.W., 2004. Ciliate populations as bioindicators at Deer Island Treatment Plant. Adv. Environ. Res. 8, 371-378.

Liu, J., Yang, M., Qi, R., An, W., Zhou, J., 2008. Comparative study of protozoan communities in full-scale MWTPs in Beijing related to treatment processes. Water Res. 42, 1907-1918.

Madoni, P., 1994. A sludge biotic index (SBI) for the evaluation of the biological performance of activated sludge plant on the microfauna analysis. Water Res. 28, 67-75.

Madoni, P., Davoli, D., Chierici, E., 1993. Comparative analysis of the activated sludge microfauna in several sewage treatment works. Water Res. 27, 1485-1491.

Madoni, P., Davoli, D., Gorbi, G., Vescovi, L., 1996. Toxic effect of heavy metals on the activated sludge protozoan community. Water Res. 30, 135-141.

Madoni, P., Davoli, C., Davoli, D., Guglielmi, L., Pergetti, M., Stefanini, C., 2005. Depurazione biologica nei fanghi attivi. Universita degli Studi di Parma; Enia S.p.A., Sede di Reggio Emilia, Italy.

Martín-Cereceda, M., Serrano, S., Guinea, A., 1996. A comparative study of ciliated protozoa communities in activated-sludge plants. FEMS Microbiol. Ecol. 21, 267-276.

Moran, C., Hall, M.E., Howel, R., 1997. Effects of sewage treatment on textile effluent. JSDC 13, 272-274.

Mortimer, M., Kasemets, K., Kahru, A., 2010. Toxicity of ZnO and $\mathrm{CuO}$ nanoparticles to ciliated protozoa Tetrahymena thermophila. Toxicology 269, 182-189.

Nicolau, A., Dias, N., Mota, M., Lima, N., 2001. Trends in the use of protozoa in the assessment of wastewater treatment. Res. Microbiol. 152, 621-630.

Nicolau, A., Martins, M.J., Mota, M., Lima, N., 2005. Effect of copper in the protistan community of activated sludge. Chemosphere 58, 605-614.

Nicolau, A., Mota, M., Lima, N., 2007. Microfauna as indicator of copper, zinc, and cycloheximide in activated sludge processes. Environ. Eng. Sci. 24, 434-445.

Papadimitriou, C., Palaska, G., Lazaridou, M., Samaras, P., Sakellaropoulos, G.P., 2007. The effects of toxic substances on the activated sludge microfauna. Desalination 211, 177-191.

Pérez-Uz, B., Arregui, L., Calvo, P., Salvadó, H., Fernández, N., Rodríguez, E., Zornoza, A., Serrano, S., 2010. Assessment of plausible bioindicators for plant performance in advanced wastewater treatment systems. Water Res. 44, 5059-5069.

Salvadó, H., Gracia, M.P., Amigo, J.M., 1995. Capability of ciliated protozoa as indicators of effluent quality in activated sludge plants. Water Res. 29, 1041-1050.

Samaras, P., Papadimitriou, C.A., Vavoulidou, D., Yiangou, M., Sakellaropoulos, G.P., 2009. Effect of hexavalent chromium on the activated sludge process and on the sludge protozoan community. Bioresour. Technol. 100, 38-43.

APHA, 1995. Standard Methods for the Examination of Water and Wastewater, 19th Ed. American Public Health Association/American Water Works Association/Water Environment Federation, Washington, DC, USA.

Yiannakopoulou, T.V., Kaimakamidou, V., 2009. Testing the reliability of protozoa as indicator of wastewater treatment plant performance. Fresenius Environ. Bull. 18, 146-157.

Zhou, K., Xu, M., Dai, J., Cao, H., 2006. The microfauna communities and operational monitoring of an activated sludge plant in China. Eur. J. Protistol. 42, 291-295.

Zhou, K., Xu, M., Liu, B., Cao, H., 2008. Characteristics of microfauna and their relationships with the performance of an activated sludge plant in China. J. Environ. Sci. 20, 482-486. 